\title{
RELATIONSHIP OF ATTITUDES AND PERCEPTIONS WITH ADHERENCE IN TREATMENT OF PULMONARY TUBERCULOSIS PATIENTS IN MEDAN, INDONESIA
}

\author{
ARLINDA SARI WAHYUNI ${ }^{1 *}$, NONI NOVISARI SOEROSO ${ }^{2}$, DIAN DWI WAHYUNI ${ }^{3}$, RINA AMELIA ${ }^{1}$, IVANA ALONA ${ }^{1}$
}

${ }^{1}$ Department of Community Medicine, Faculty of Medicine, Universitas Sumatera Utara, Indonesia. ${ }^{2}$ Department of Pulmonary and Respiratory, Faculty of Medicine, Universitas Sumatera Utara, Indonesia. ${ }^{3}$ Department of Microbiology, Faculty of Medicine, Universitas Sumatera Utara, Indonesia. Email: arlinda@usu.ac.id

Received: 07 March 2018, Revised and Accepted: 25 March 2018

ABSTRACT

Objective: This study aimed to analyze the relationship of attitudes and perceptions about tuberculosis (TB) with adherence to the treatment of TB patients in Medan.

Methods: A quantitative cross-sectional design. The target population was all patients who admitted to seven primary health centers (PHCs) in Medan. Samples were new TB patients aged $>18$ years old, with the result of acid-fast bacilli $(+)(n=100)$. Assessment of behavioral adherence, attitudes, and perceptions of treatment were done based on treatment behavior instruments that had been validated and analyzed by the Chi-square test and logistic regression.

Results: The results showed that $55 \%$ of the patients adhered to their medication. There was a relationship between attitude and adherence of TB treatment $(\mathrm{p}<0.05)$. However, there is no perception correlation with treatment adherence ( $>0.05)$. A good attitude increased 3.7 (95\% confidence interval 1624; 8549) times for adherence to TB treatment.

Conclusions: The positive attitude of the TB patients improved TB treatment behavior. Structured education provided by doctors and TB officers in PHC should be done to improve the knowledge and attitude of TB patients.

Keywords: Attitude, Perception, Adherence to treatment, Tuberculosis patients.

(C) 2018 The Authors. Published by Innovare Academic Sciences Pvt Ltd. This is an open access article under the CC BY license (http://creativecommons. org/licenses/by/4. 0/) DOI: http://dx.doi.org/10.22159/ajpcr.2018.v11s1.26612

\section{INTRODUCTION}

Tuberculosis (TB) treatment still remains a big challenge in Indonesia although the management has referred to directly observed treatment short course chemotherapy (DOTS) strategy. The long-term treatment of TB disease is the major factor that is associated with patient's failure to comply and adhere the treatment [1]. Numerous patients do not take TB drugs regularly and not as the suggested dosage and time.

Several studies regarding TB adherence have been widely conducted in many places in Indonesia. One of them is Nursiswati's study conducted in a number of health centers in Sumedang. The study found that there were only $37.3 \%$ of the TB patients who adhered the treatment. The result of the study also reported that an intensive phase, $68.42 \%$ of the respondents adhered the treatment. At the intermittent phase, the percentage of the TB patients who adhered the treatment was $50 \%$. In un adherence respondent group, $13 \%$ of the respondent took the drugs irregularly, $6 \%$ did not take the drugs as suggested, and $81 \%$ did not take the drugs timely [2]. While another similar study showed that adherence of TB patients treatment in Medan Health Centres was $71.1 \%$. This result is affected by knowledge, attitudes, health belief toward the disease suffered by the patients and by the role of Drug Observer and health officers [3].

In adherent behavior toward drinking anti-TB drugs may lead to serious problems. This may increase Mycobacterium TB resistance toward the TB drug, TB relapse, and morbidity and mortality of TB patients. In adherent, behavior may also increase the risk of infection to community and Multidrug Resistance cases [4].

Appropriate and adequate TB treatment depends on management behavior of the treatment from TB patient and also the doctor who treats them, simple patient treatment behavior is often called as compliance [5].

Principally, adherence is not similar to with compliance. Adherence is associated with patient behavior to adhere on the doctor's suggestion which is also associated with patients understanding about the disease information and its management $[1,5]$, so that patients implicate on high commitment to follow doctor's recommendation and suggestion consistently.

The development of TB management which is based on adherence behavior and indicators to establish this behavior is important to be implicated to overcome treatment behavior problems and negative implications. TB management using DOTS strategy really need to be refined using this adherence concept because this concept and its concordance directly focus on the patient and the health caregiver, and not merely on the role of PMO of whose supporting quality is difficult to monitor and tends to be less optimal.

\section{METHODS}

This was a quantitative study using explanatory survey with crosssectional design which aimed at explaining the correlation between independent and dependent variables. It was conducted in 7 Primary Health centers in Medan city, and the ethical clearance was obtained from Medical Faculty/RS Haji Adam Malik Ethical Research Board and Medan Health Office.

The population of the study was all TB patients in Category I (newly diagnosed) aged $\geq 18$ years old. The recruited samples are those who match the inclusion criteria of Category I TB patients diagnosed to have acid-fast bacilli positive smear, aged $\geq 18$ years old, readily signing the informed concern, meanwhile excluded criteria of TB patients were patients with comorbid disease such as cancer, HIV, diabetes mellitus, or those patients having steroid regiment.

The sample size was based on the formula of the hypothetical test of one population for cross-sectional design with an alpha value of $5 \%$ and beta value of $20 \%$ [6]. Based on this calculation, the sample size of this population was 100 people. The respondents of this study research 
were ongoing the intensive treatment phase. We conducted interview using structured questionnaire about adherence behavior, attitude, and perception which had been validated (alpha Cronbach $>0.6$ ).

The collected data were analyzed using univariate, bivariate, and multivariate analysis. Distribution frequency was used for descriptive analysis, Chi-square test for bivariate analysis, and logistic regression for multivariate analysis.

\section{RESULTS}

The study was conducted in 2016 from March to August in 7 Primary Health centers in Medan: Puskesmas Belawan, Amplas, Teladan, Helvetia, Johor, Padang Bulan, and danSentosa. The respondent characteristics included sex, age, education level, occupation, tribe, and marital status [Tables 1-3].

This study found that most of the respondents are male (69\%) and aged $\leq 40$ years old (45\%). Based on the education level, $53 \%$ of the respondent was from high-level education (high school and university). In average, the respondents salary was $<2$ million (83\%). The percentage of the respondents who are employed was $64 \%$. Most of the respondent tribe was Bataknese (57\%) and in married status $(68 \%)$.

The study found that $55 \%$ of the TB patients adhered on the treatment. There was a correlation between attitude and adherence $(p \leq 0.05)$, and no correlation between sociodemographic characteristics and perception with treatment adherence $(p>0.05)$

The result of analysis on logistic regression showed that positive attitude of a TB patient correlated 3.7 times (95\% CI 1.624; 8.549 ) as much adherence behavior of TB treatment in Primary Health centers in Medan treatment in Puskesmas in Medan.

\section{DISCUSSION}

The study found that $55 \%$ of the TB patients adhered to the treatment during the intensive phase. In this study, adherence means that the TB patient is obedient on the doctor advice and concordantly takes the drugs and has a good understanding of his disease $[1,5]$

Adherence principle may not be thought to be similar to compliance. Compliance means that the patients passively follow the doctor's orders

Table 1: Characteristic distribution of TB patients in Medan

\begin{tabular}{ll}
\hline Characteristic & n (\%) \\
\hline Sex & $69(69)$ \\
$\quad$ Male & $31(31)$ \\
Female & \\
Age & $45(45)$ \\
$\quad<40$ years old & $42(42)$ \\
$40-59$ years old & $13(13)$ \\
$\geq 60$ years old & \\
Education & $47(47)$ \\
Low (SD, SMP) & $53(53)$ \\
High (SMA, D-III, S1) & \\
Salary & $83(83)$ \\
Low (<2 million) & $17(17)$ \\
Enough ( $\geq 2$ million) & \\
Occupation & $36(36)$ \\
Unemployed & $64(64)$ \\
Employed & $57(57)$ \\
Tribe & $29(29)$ \\
Bataknese & $14(14)$ \\
Javanese & $68(68)$ \\
Etc. & $32(32)$ \\
Marital status & \\
Married & \\
Not married & \\
\hline TB: Tuberculosis &
\end{tabular}

without patient's role for the undergoing treatment [5]. Building a strong commitment in TB treatment needs doctors and TB officers' role on providing an explanation about the disease and treatment to the patients.

In addition to doctors and health officers' role at the health service centers of TB, adherence behavior for the treatment is affected by various factors such as social economic and community structure, and individual patients' factors which consist of demographic characteristics and behavior factors such as attitude and belief, values, health-illness concept, treatment regiment complexity, supportive relationships of health providers, and health service models $[1,7,8]$. In this study, it is found that there is no correlation between characteristics of demography and perception (patient's belief) with TB treatment adherence ( $p>0.05)$. The major factor that links patients to adherence behavior is patient's attitude toward the treatment. Out of the $55 \%$ patients who adhere the treatment, $67 \%$ has positive (good) attitude. Patients with good attitude will be 3.7 times more adherent than patients with less good attitude. This finding is similar with previous studies conducted by Rugun et al. [3] which resulted that there is a correlation between TB patient attitude and compliance in Medan city. According to Saranya et al. attitude can be improved by providing good counselling to TB patients [9].

This study also shows that patients with bad perception are higher in the less adherent population who are on TB treatment. The study includes several TB stigma statements in the perception variables.

Table 2: The relationship between sociodemographic characteristics, attitude, and perception with TB treatment adherence of TB patients

\begin{tabular}{|c|c|c|c|}
\hline \multirow[t]{2}{*}{ Variables } & \multicolumn{2}{|c|}{ Adherence,n (\%) } & \multirow[t]{2}{*}{$\mathbf{p}^{*}$} \\
\hline & Good & Less good & \\
\hline Sex & & & 0.983 \\
\hline Male & $38(69.1)$ & 31 (68.9) & \\
\hline Female & $17(30.9)$ & $14(31.1)$ & \\
\hline \multicolumn{4}{|l|}{ Age (years) } \\
\hline$<40$ & $24(43.6)$ & $21(46.7)$ & 0.317 \\
\hline $40-59$ & $26(47.3)$ & $16(35.6)$ & \\
\hline$>60$ & $5(9.1)$ & $8(17.8)$ & \\
\hline Education & & & 0.952 \\
\hline Low & $26(47.3)$ & $21(46.7)$ & \\
\hline High & $29(52.7)$ & $24(53.3)$ & \\
\hline \multicolumn{4}{|l|}{ Salary } \\
\hline Low & $44(80$ & 39 (86.7) & 0.377 \\
\hline Enough & $11(20$ & $6(13.3)$ & \\
\hline Occupation & & & 0.079 \\
\hline Unemployed & $24(43.6)$ & $12(26.7)$ & \\
\hline Employed & $31(56.4)$ & $32(73.3)$ & \\
\hline \multicolumn{4}{|l|}{ Marital status } \\
\hline Married & $37(67.3)$ & $31(68.9)$ & 0.386 \\
\hline Not married & $18(32.7)$ & $14(31.1)$ & \\
\hline \multicolumn{4}{|l|}{ Attitude } \\
\hline Good & $37(67.3)$ & $16(35.6)$ & $0.002^{* *}$ \\
\hline Less good & $18(32.7)$ & $29(64.4)$ & \\
\hline \multicolumn{4}{|l|}{ Perception } \\
\hline Good & $29(52.7)$ & $20(44.4)$ & 0.410 \\
\hline Less good & $26(47.3)$ & 25 (55.6) & \\
\hline
\end{tabular}

${ }^{*}$ Chi-square, ${ }^{* *}$ significant. TB: Tuberculosis

Table 3: Analysis result of rapid correlation of attitude and TB treatment adherence

\begin{tabular}{llllll}
\hline Variable & Constanta & B & p $^{*}$ & PR & 95\% CI PR \\
\hline Attitude & -2.154 & 1.315 & 0.002 & 3.726 & $1.624-8.549$ \\
\hline
\end{tabular}

*Logistic regression. TB: Tuberculosis, PR: Prevalence ratio, CI: Confidence interval 
The perception of stigmatization poses a great barrier to treatment seeking and medication compliance, and the provision of healthcare services $[10,11]$.

TB control program in Medan can be considered relatively good which is indicated by the availability of doctors and health officers who focus on TB service in each Health center [12]. However, with low adherence behavior of TB patients, it is a necessity to increase doctors and health officers' role in providing education to TB patients to increase their attitude and behavior toward the treatment.

\section{CONCLUSION}

Most of the TB patients in Medan adhere on the TB treatment and have good attitude and perception. Demographic characteristics of this study are predominantly male, in productive age $\geq 18$ years old, high education level (high school and university), low salary ( $<2$ million), Batak tribe, and married.

Positive attitude of TB patient will increase treatment adherence behavior 3.7 times more than patient with less good attitude. It is necessary to provide a structured education by doctors and TB officers of Primary Health centers to increase TB patient's knowledge and attitude in Primary Health centers in Medan.

\section{ACKNOWLEDGMENT}

This study was funded by Ministry of Health, Ministry of Research, Technology, and High Education Republik Indonesia. There was no conflict of interest for the publication of this study. The research team extended their gratitude to the Rector of Universitas Sumatera Utara for the support of this study.

\section{REFERENCES}

1. WHO. Adherence to Long Term Therapies: Evidence for Action. Geneva: WHO Library Cataloguing-in-Publication Data; 2003.

2. Nursiswati. Compliance Description of TB Patient on OAT Treatment at Three Basic Health Sevices in Sumedang District. Nursing Faculty: Universitas Pajajaran; 2009.

3. Rugun HN, Amir ZA, Abidin A, Aman TN, Wahyuni AS. Factors Related to Conversion Failure of Pulmo TB Patient Category I at Final Treatment of Intensive Phase in Medan City. Majalah Kedokteran Nusantara. Medan: Health Office of North Sumatera Province; 2014.

4. National Tuberculosis Control Programme. National Strategic Plan for Tuberculosis Control 2012-2017. New Delhi: Central TB Division, Directorate General of Health Services; 2017. p. 32-7

5. Revised National Tuberculosis Control Programme. National Strategic Plan for Tuberculosis Control 2012-2017. New Delhi: Central TB Division, Directorate General of Health Services; 2017. p. 32-7.

6. Sastroasmoro S, Ismael S. Basic Clinical Research Methods. Jakarta: Sagung Seto; 2012.

7. Munro SA, Lewin SA, Smith HJ, Engel ME, Fretheim A, Volmink J. Patient adherence to tuberculosis treat men: A systematic review of qualitatif research. PLoS Med 2007;4:1230-45.

8. Widjanarko B. Factors that influence treatment adherence of tuberculosis patients living in Java, Indonesia. Dove Press J 2009:231-38.

9. Saranya P, Swathi S, Kousalya K, Praveen D. A prospective interventional study of knowledge, attitude, and practice (KAP) towards tuberculosis among patients with Koch's disease. Int J Pharm Pharm Sci 2015;8:58-61.

10. Ruzyanei NN, Wan Salwina W, Tuti Iryani M, Rozhan M, Shamsul A, Zasmani S. Psychosocial factors influencing truancy in high risk secondary schools in Kuala Lumpur. Interactions between psychiatric disorder and physical illness. MJP 2009;18:14-21.

11. Ahmad S, Ismail NE. Stigma in the lives of asthma patients: A review from the literature. Int J Pharm Pharm Sci 2015;7:40-6.

12. Health Profile of North Sumatera Province Year 2012. Health Office of North Sumatera Province; 2013. 